International Journal of Engineering \& Technology, $7(3.2)(2018) 436-441$
International Journal of Engineering \& Technology
Website $:$ www.sciencepubco.com/index.php/IJET
Research paper

\title{
Compressed Flexible Steel Reinforced Concrete Elements Investigation
}

\author{
Leonid Storozhenko ${ }^{1}$, Pavlo Semko ${ }^{2}$, Olena Yefimenko ${ }^{3 *}$ \\ ${ }^{1}$ Poltava National Technical Yuri Kondratyuk University, Ukraine \\ ${ }^{2}$ Poltava National Technical Yuri Kondratyuk University, Ukraine \\ ${ }^{3}$ Poltava National Technical Yuri Kondratyuk University, Ukraine \\ *Corresponding Author E-Mail: Lenysia_17.02@Ukr.Net
}

\begin{abstract}
Stress-strain state and compressed flexible steel-reinforced concrete elements resistance capacity are investigated in the work. The experiment program is complied and steel reinforced concrete elements calculations methods are analyzed. Experimental sample design drawings are shown. Raw materials physical and mechanical properties are determined. Steel reinforced-concrete elements experimental and research studies have been carried out. Coboundary dependences N-M for steel reinforced concrete elements construction method is proposed. Resistance capacity diagrams for steel reinforced concrete elements are constructed depending on the element height and the applied eccentricity.
\end{abstract}

Keywords: bearing capacity, sheet reinforcement, stress-strain state steel-reinforced concrete,

\section{Introduction}

Compressed steel reinforced concrete elements are one of the most effective composite materials used in construction. They can be used not only as columns or racks but as bearing elements in a core systems variety, including overlays or coatings. They can also be part of the designs of stationary marine, oil platforms or used in the mining industry, as the construction of the fortification of mining. In general, they consist of: bases like the bottom part, under loads pre-assisted transfer to the building foundations; the rod is the main element and the hook where the above structures are based [5, 6]. One of cross-sections effective types is the version presented in Fig. 1, 2 where the steel parts are concentrated in the form of strips at the maximal distance from the center of gravity, which is the optimal variant of using the material from the bearing capacity conditions, and the space between them is filled with concrete, to ensure overall stability.

\section{Main Body}

Various parameters compressed-bent elements with sheet reinforcement experimental studies were carried out. Based on the papers review and experiments program development was planned:

- To make prototype steel-reinforced concrete racks with sheet reinforcement in height $1000 \mathrm{~mm}, 1700 \mathrm{~mm}, 2400 \mathrm{~mm}$;

- To conduct experimental studies centrally and centrally compressed elements with sheet reinforcement;

- To discover during the study the work peculiarities and steelconcrete elements destruction character [2].

When compiling the experiment program, it was considered that the bearing capacity and element stress-strain state depend on the constructive solution, load application eccentricity and the physi- cal and raw materials mechanical properties. The task was to determine experimentally the strength and work peculiarities under load of compressed elements with sheet reinforcement. For experimental research steel-concrete racks of different height, filled with heavy concrete were used. Prototypes characteristics are given in Table 1.

\begin{tabular}{|c|c|c|c|}
\hline Sample series & Samples characteristics & $\begin{array}{l}\text { Length L, } \\
\text { mm. }\end{array}$ & $\begin{array}{r}\mathrm{e}_{\mathrm{o}}, \\
\mathrm{mm} .\end{array}$ \\
\hline SB-PD-10-1 & $\begin{array}{l}\text { with sheet reinforcement, filled } \\
\text { with concrete }\end{array}$ & 1000 & 0 \\
\hline SB-PD -10-2 & $\begin{array}{l}\text { with sheet reinforcement, filled } \\
\text { with concrete }\end{array}$ & 1000 & 25 \\
\hline SB-PD -10-3 & $\begin{array}{l}\text { with sheet reinforcement, filled } \\
\text { with concrete }\end{array}$ & 1000 & 50 \\
\hline SB-PD -17-1 & $\begin{array}{l}\text { with sheet reinforcement, filled } \\
\text { with concrete }\end{array}$ & 1700 & 0 \\
\hline SB-PD -17-2 & $\begin{array}{l}\text { with sheet reinforcement, filled } \\
\text { with concrete }\end{array}$ & 1700 & 25 \\
\hline SB-PD -17-3 & $\begin{array}{l}\text { with sheet reinforcement, filled } \\
\text { with concrete }\end{array}$ & 1700 & 50 \\
\hline SB-PD -24-1 & $\begin{array}{l}\text { with sheet reinforcement, filled } \\
\text { with concrete }\end{array}$ & 2400 & 0 \\
\hline SB-PD -24-2 & $\begin{array}{l}\text { with sheet reinforcement, filled } \\
\text { with concrete }\end{array}$ & 2400 & 25 \\
\hline SB-PD -24-3 & $\begin{array}{l}\text { with sheet reinforcement, filled } \\
\text { with concrete }\end{array}$ & 2400 & 50 \\
\hline
\end{tabular}

Manufacturing complex steel-concrete constructions process consisted of two parts: frames fabrication and samples manufacture. Steel sheets were used for the experimental samples production $\mathrm{t}=4 \mathrm{~mm}$, cross type valves class A-I $\varnothing 6 \mathrm{~mm}$. The sample leight was 1000,1700 , $2400 \mathrm{~mm}$, section 100x100 mm [1].

Proceeding from the set task, experimental samples cross sections reinforcement schemes for the experiment were developed. The work peculiarities under load and steel reinforced concrete samples resistance capacity loss character with steel sheets external reinforce- 
ment depending on the height and efforts pplication eccentricity, as well as central compressed elements filled with concrete comparative work characteristics were compared experimentally.

The following samples series were made:

1. With reinforcement with sheet reinforcement in leight $1000 \mathrm{~mm}$, filled with concrete grade $\mathrm{C} 20 / 25$. Initial eccentricity $\mathrm{e}_{\mathrm{o}}=0 ; 25 ; 50$ mm (SB-PD -10-1, SB-PD -10-2 SB-PD -10-3 series);

2. With reinforcement with sheet reinforcement in leight $1700 \mathrm{~mm}$, filled with concrete grade $\mathrm{C} 20 / 25$. Initial eccentricity $\mathrm{e}_{\mathrm{o}}=0 ; 25 ; 50$ mm (SB-PD -17-1, SB-PD -17-2, SB-PD -17-3 series).

3 . With reinforcement with sheet reinforcement in leight $2400 \mathrm{~mm}$, filled with concrete grade $\mathrm{C} 20 / 25$. Initial eccentricity $\mathrm{e}_{\mathrm{o}}=0 ; 25 ; 50$ mm (SB-PD -24-1, SB-PD -24-2, SB-PD -24-3 series).

When marking letters and numbers indicated: $\mathrm{SB}-$

samples filled with concrete, the first figure is the sample height, respectively: $10-1000 \mathrm{~mm}, 17-1700 \mathrm{~mm}, 24-2400 \mathrm{~mm}$,

the second digit is the initial eccentricity, respectively: $1-0 \mathrm{~mm}$ (without eccentricity, central compression), $2-25 \mathrm{~mm}, 3-50 \mathrm{~mm}$, the letters PD-plate are placed tangentially to the moment of action. In all series three samples were tested - twins.

Experimental samples designs are shown on (Fig. 1) and (Fig.2).

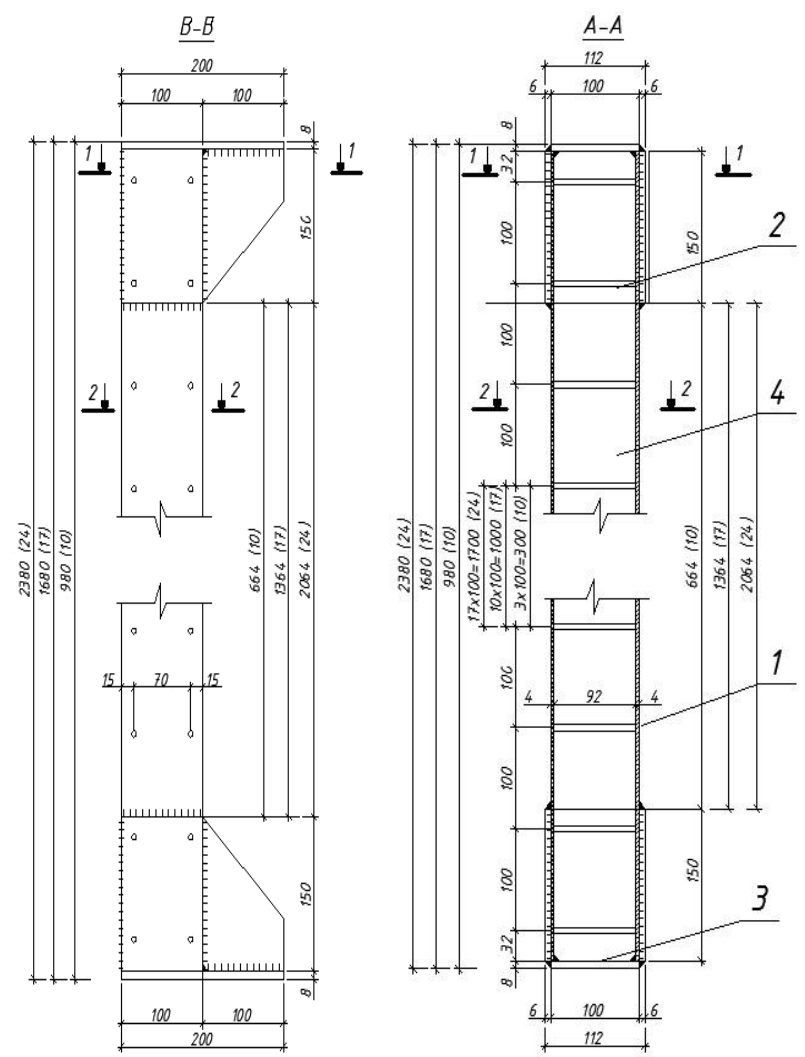

Fig. 1. Experimental samples designs

End plates and transverse rods are interconnected by a sheet reinforcement, which simultaneously performs the formwork function. Rods transverse armature is welded at a distance $100 \mathrm{~mm}$ from each other by semi-automatic welding.
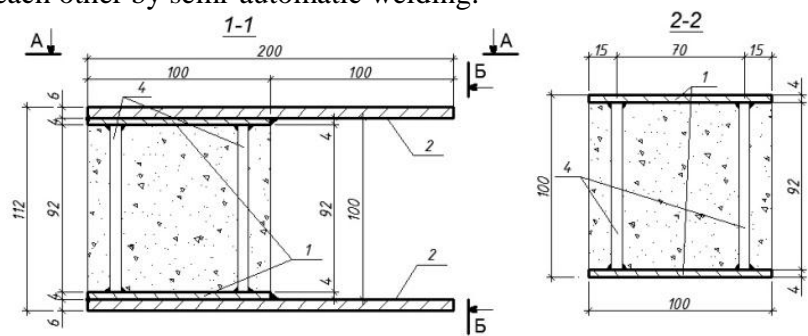

Fig. 2. Experimental samples designs

A rack with sheet reinforcement is shown in Figure 2. The stand is composed of 1 - sheet-iron plate, 2 - steel reinforcing rod, 3 full metal, 4 - concrete.

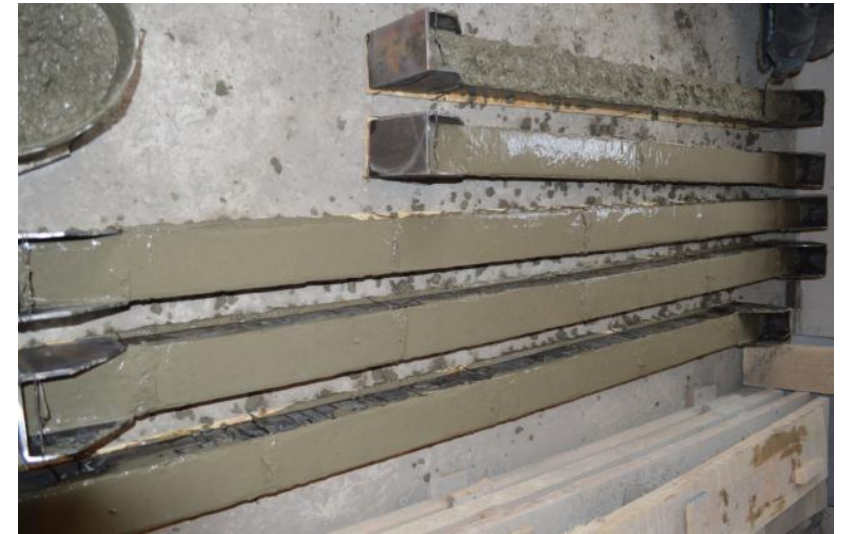

Fig. 3. Filling samples with concrete

During concreting, welded in the box form sheets positions 1 and 3 interconnected with the help of position rods 2 , are placed on a pallet and filled with concrete in a horizontal position (Fig. 3). The external reinforcement serves as an embedded steell. Transverse armature bars were welded to the sheet armature in the brands by semi-automatic welding. The transverse rods are placed in parallel with two rows. Steel-concrete products concreting took place at the reinforced concrete structures plant's factory. Steel rod mechanical characteristics he determination and sheet fittings was carried out on standard samples in accordance with the norms. Steel samples testing were carried out on a tear-off machine TMS-50 with simultaneous recording of the tension chart.

Test samples were taken at age 28 days and more. Tests were conducted on the press 2 PG-125 depicted on (Fig. 4).

Load step (0.05 - 0.1) from $\mathrm{N}$ destructive. Posterior and transverse deformations were measured using electrotrotose resistors at all load stages.
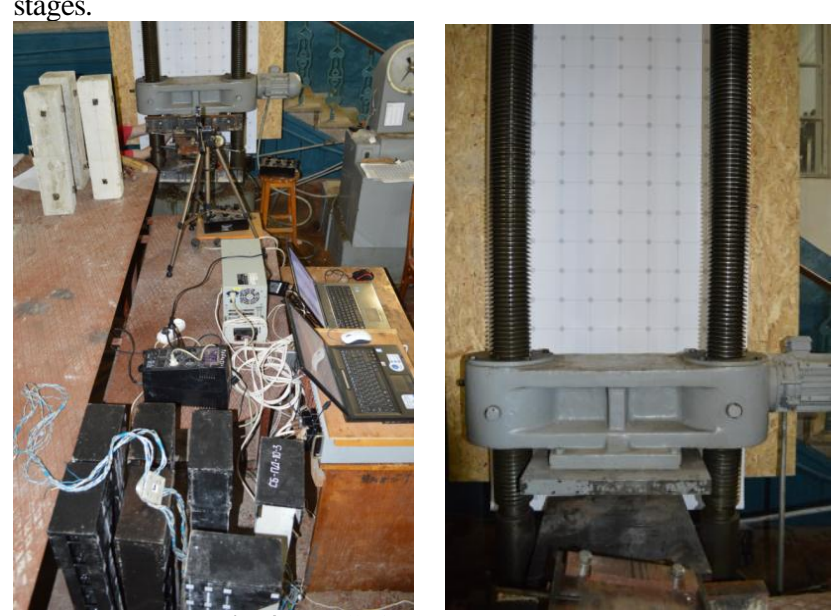

Fig. 4. Installation. press $2 \mathrm{PG}-125$

At all loading stages, there were marked by destruction characteristic peculiarities and deformations distribution on the samle height, the cracks development in the concrete, as well as element deflections growth intensity. All samples were destroyed. Devices at this time showed a significant increase in deformations, and the arrow of the force meter slowly moved in the opposite direction. After load removal, the remaining deformations remained clearly evident in the samples, the longitudinal axis of the sample remained distorted. In addition, longitudinal deformations were measured using clock indicators with a price of $0,01 \mathrm{~mm}$ divisions on the basis of $200 \mathrm{~mm}$. The deflections in the experimental elements were measured with the help of Aistov proginomers. Electro tensoresistor is placed in longitudinal direction on samples of different heights and with load application different eccentricity. 


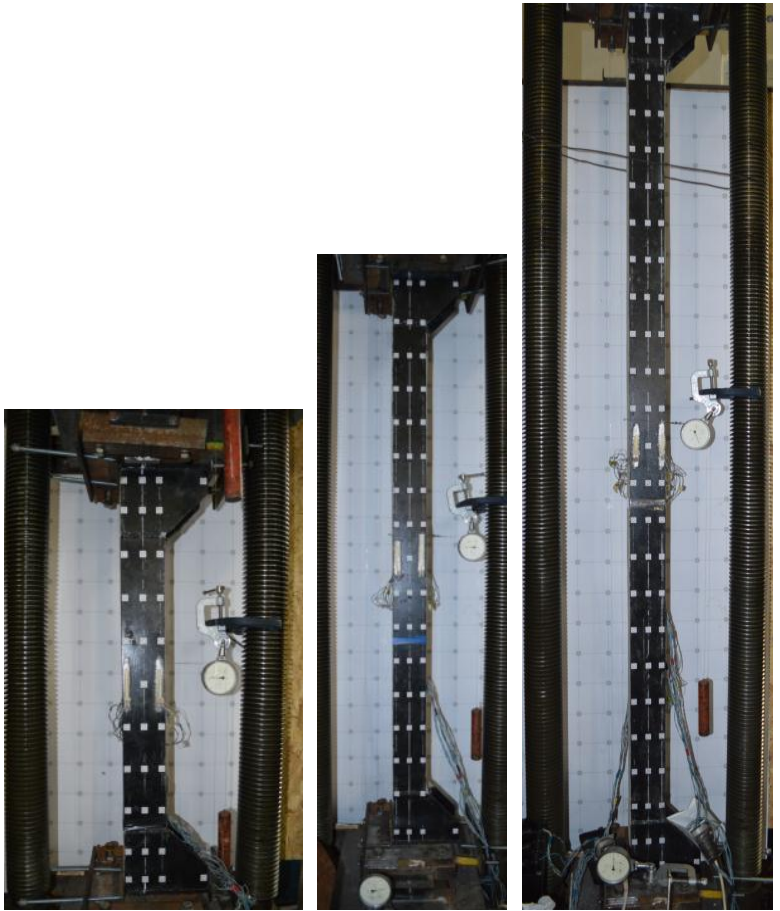

Fig. 5. Experimental samples during the test

\subsection{Raw material physical and mechanical properties}

For prototype samples production, concrete grade was accepted C20/25 for durability, the data on the composition are given in table. 2. For the preparation of concrete, granite crushed stone was used (faction $10-20 \mathrm{~mm}$ ), river sand $\left(\mathrm{M}_{\mathrm{K}}=1,58\right)$. As a binding substances portland cement was used PC -400 , with activity 400 .

Table 2. Concrete composition used to make prototype samples

\begin{tabular}{|c|c|c|}
\hline Material & Unit & Number \\
\hline Cement & $\mathrm{Kg}$ & 500 \\
\hline Sand & $\mathrm{Kg}$ & 600 \\
\hline Broken-stone & $\mathrm{Kg}$ & 1100 \\
\hline WIC & - & 0,5 \\
\hline
\end{tabular}

Concrete test samples strength is determined by testing the cubes $150 \times 150 \times 150 \mathrm{~mm}$ and prisms $150 \times 150 \times 600 \mathrm{~mm}$. Broken stones and prisms tests were performed in parallel with basic samples tests on the press $2 \mathrm{PG}-125$ aged 28 days. Concrete strength prism was $\mathrm{Rb}=19,6 \mathrm{MPa}$. Elasticity initial module $\mathrm{Eb}=2,4 \times 10^{4} \mathrm{MPa}$ Concrete longitudinal and transverse deformations according to the mesuared value graphs were built and given in Fig. 6

The measured deformations calculated the coefficient of transverse deformation $v \mathrm{~b}$ (Poisson's coefficient) and the initial elasticity modulus $\mathrm{Eb}$, as well as graphs of their variations depending on the stresses. Changes in the coefficient of transverse deformation $v \mathrm{~b}$ and deformation module Eb are shown in Fig. 7.

$\sigma_{\mathrm{b}}, \mathrm{MPa}$

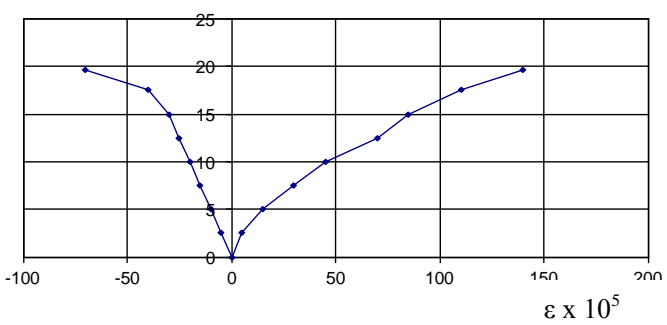

Fig. 6. Longitudinal and transverse strains from stresses dependence

The measured deformations calculated the coefficient of transverse deformation $v \mathrm{~b}$ (Poisson's coefficient) and the initial elasticity modulus $\mathrm{Eb}$, as well as graphs of their variations depending on the stresses.
Changes in the coefficient of transverse deformation $v b$ and deformation module Eb are shown in Fig. 7.
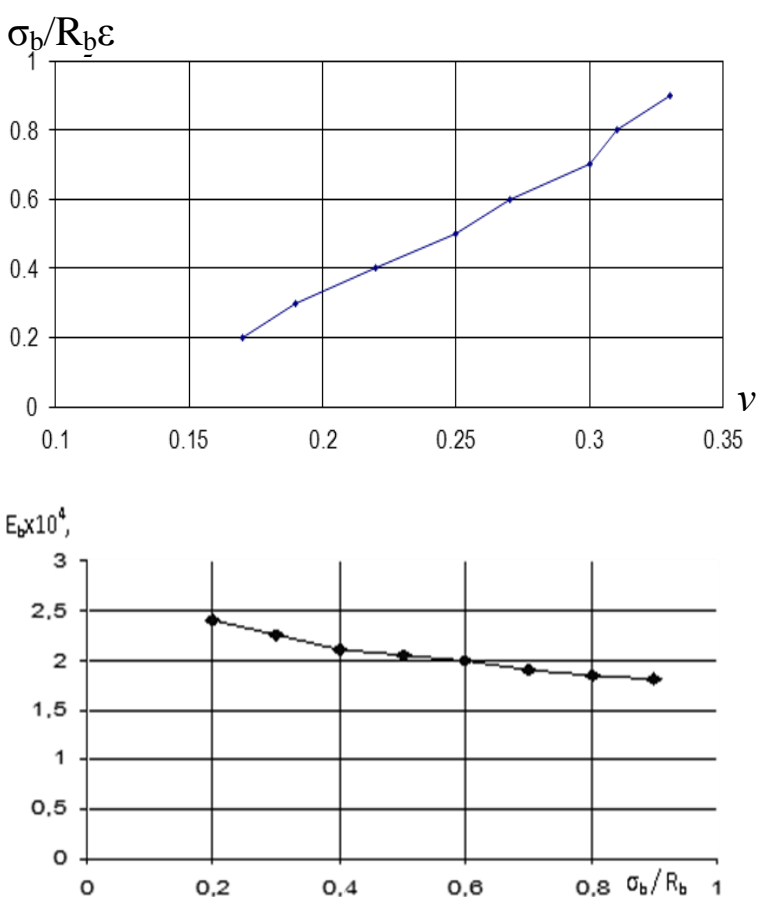

Fig. 7. Transverse deformation coefficient dependence $v b$ and deformation module Eb concrete stress value

According to figure 7 It is evident that the deformation module with increasing stresses in concrete decreases a bit, which indicates plastic deformations development. As the stress increases, the transverse deformation coefficient $v b$ increases, which indicates micro and macrocracs development in accordance with the O.Ya. Berg Theory. The magnitude $v b$ with increasing stresses varied from 0.17 to 0.32 .
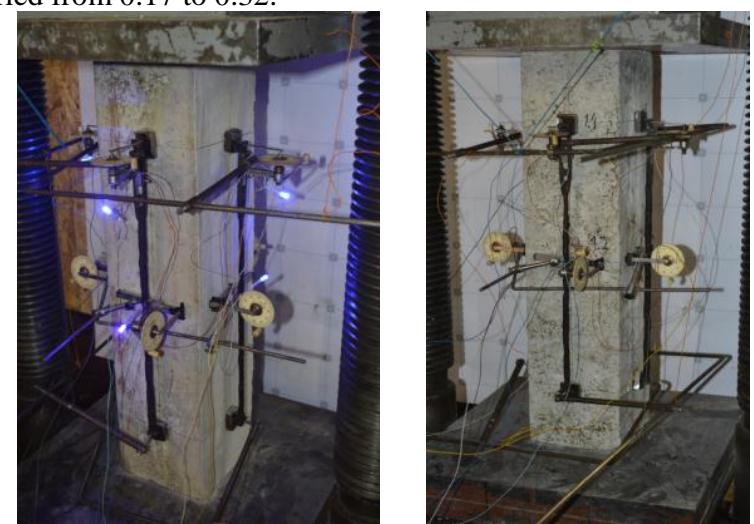

Fig. 8. Concrete prisms during the test
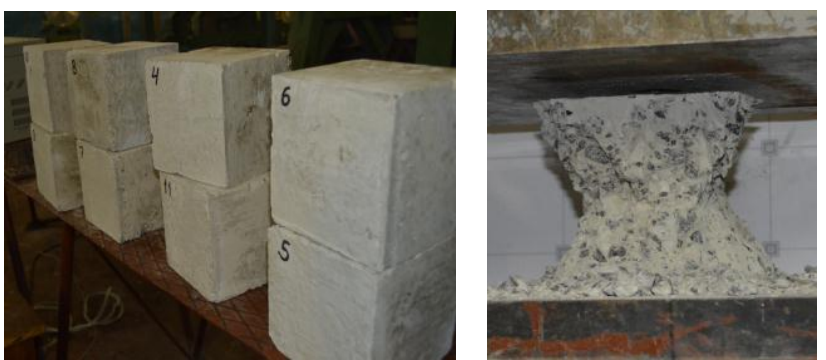

Fig. 9. Concrete broken-stone during the test

Table 3 shows steel physical and mechanical characteristics, where steel-reinforced concrete elements were used for the examination of samples tested in accordance with GOST $1497-84 . \sigma_{y}-$ 
is the stress at which flow begins, and $\sigma_{u}$ is temporary steel resistance.

Table 3. Physical and mechanical steel characteristics

\begin{tabular}{|c|c|c|c|c|c|}
\hline $\begin{array}{c}\text { Section, } \\
\mathrm{mm}\end{array}$ & $\begin{array}{c}\text { Thickness, } \\
\mathrm{mm}\end{array}$ & $\begin{array}{c}\text { Yield limit } \\
\sigma_{y}, \mathrm{MPa}\end{array}$ & $\begin{array}{c}\text { Tem- } \\
\text { poral } \\
\text { resis- } \\
\text { tance } \\
\sigma_{u}, \mathrm{MPa}\end{array}$ & $\sigma_{y}, / \sigma_{u}$ & $\begin{array}{c}\text { elasticity } \\
\text { module } \\
\mathrm{E}_{\mathrm{S}} \times 10^{5}, \\
\mathrm{MPa}\end{array}$ \\
\hline $100 \times 100$ & 4 & 280 & 390 & 0,71 & 2,07 \\
\hline
\end{tabular}

As a research result the dependencies were obtained $\sigma_{s}-E_{s}$ for steel strips and tensile testers. Relation $\sigma_{y} / \sigma_{u}$ is approximately $0,6-0,8$, which corresponds to the steel performance on tension. The site absence of yield during metal strips test at the gap in determining steel physical and mechanical characteristics due to the fact that samples manufacturing process was a metal natural reveted.
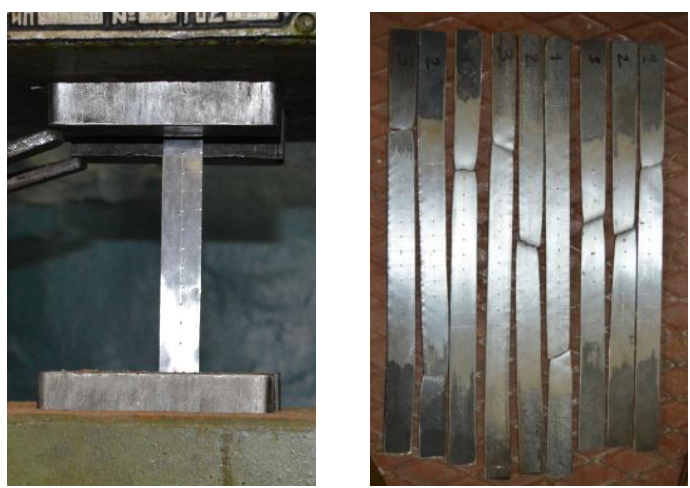

Fig. 10. Steel strips after and before the test

Fittings test results are presented in Table. 4 and steel deformation diagram is desplayed in Figure 10.

Table 4. Reinforcement Physical and mechanical properties

\begin{tabular}{|c|c|c|c|c|c|}
\hline $\begin{array}{c}\text { Armatu- } \\
\text { re }\end{array}$ & Diameter & $\begin{array}{c}\text { Yield } \\
\text { limit } \sigma_{\mathrm{y}}\end{array}$ & $\begin{array}{c}\text { Temporal } \\
\text { resistance } \\
\sigma_{\mathrm{u}}\end{array}$ & $\sigma_{\mathrm{y}} / \sigma_{\mathrm{u}}$ & $\begin{array}{c}\text { Elasticity } \\
\text { module } \\
\text { Es x } 10^{5}\end{array}$ \\
\hline A-III & 6 & 491 & 620 & 0,80 & 2,1 \\
\hline
\end{tabular}

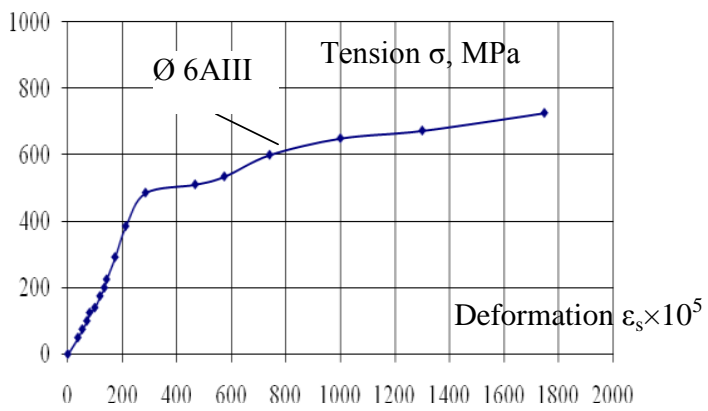

Fig. 11. Reinforcing steel deformation diagram

Concrete prisms and cube testing, reinforcing rods and steel strips to determine strengh physical and mechanical characteristics and these materials deformation was carried out simultaneously with the study of compressed steel reinforced concrete elements in accordance with the existing norms.

\subsection{Steel reinforced concrete structures theoretical cal- culation}

To determine the steel-concrete elements bearing capacity presented in the drawings 1,2 necessary calculation of cross-sectional strength for axial and centrifugal compression (with eccentricities 0,25 and 0,5 from the sample leight) and from overall stability loss condidions.
According to the Eurocode 4 paragraph 6.7 [3] recommendations bearing cross-sectional cross-section of steel-concrete element, axial compression is determined by the formula:

$N_{p l, R d}=A_{a} f_{y d}+0,85 A_{c} f_{c d}$,

where $A_{a}-$ steel pipe area;

$A_{c}$ - concrete core area;

$f_{y d}-$ steel yield strength estimated value;

$f_{c d}$ - concrete strength on compression estimated value.

To determine the resistance capacity for noncentric compression with eccentricities applying load to 0,5 section height including, it will give a steel concrete section to steel using the well-known formula:

$\sigma=N / A \pm M / W \leq R_{y}$,

where $\sigma$-tension;

$N$ - longitudinal force;

$M$ - bending moment;

$M=e \cdot N$,

After bringing the concrete to steel we obtain from the formula (2) the value of the marginal force for the resulting cross section:

$N=R_{y} \cdot A_{\text {red }} /\left(1+e \cdot A_{\text {red }} / W_{\text {red }}\right)$

where $A_{\text {red }}, W_{\text {red }}-$ area and reduced section resistance moment, which are determined by the formulas (5) and (6):

$A_{\text {red }}=2 \cdot t \cdot h+(b-2 t) \cdot R_{b} / R_{y}$

$W_{\text {red }}=\left(2 t+b \cdot R_{b} / R_{y}\right)$
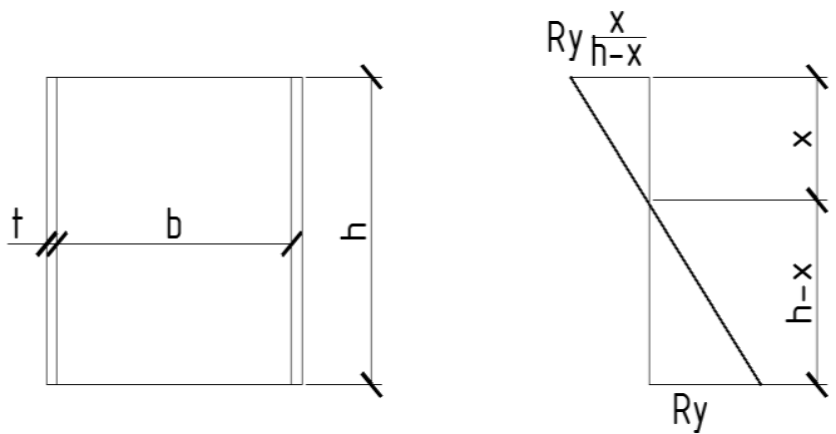

Fig. 12. Element circuit diagram

While mean tensile forces in the section (pure bending case) appeared, it should be taken into account that concrete located in the tensile zone does not actually affect the element resistance bearing capacity. To do it, determine the location of the neutral line ( $\mathrm{x}-$ height of the compressed zone), which can be obtained from the equilibrium conditions of the cross section:

$(h-x) \cdot 2 t \cdot R_{y} / 2=\left(2 t+t \cdot b / t \cdot R_{b} / R_{y}\right) \cdot R_{y} / 2 \cdot x / h-x$,

Where is the compressed zone height $(\mathrm{x})$ equal to:

$x=h \cdot \sqrt{\frac{4 \cdot t^{2} \cdot R_{y}^{2}}{b^{2} \cdot R_{b}^{2}}+\frac{2 \cdot t \cdot R_{y}}{b \cdot R_{b}}}-\frac{2 \cdot t \cdot R_{y}}{b \cdot R_{b}}$,

The value of the maximum bending moment for a pure bend can be determined by the formula (9): 


$$
\begin{aligned}
& M=2 t(h-x) \cdot R_{y} / 2 \cdot 2(h-x) / 3+2 t x \cdot R_{y} \cdot x / 2(h-x) \cdot 2 x / 3+ \\
& +b x\left(R_{b} / R_{y} \cdot R_{y} \cdot x / z(h-x) \cdot 2 x / 3\right)
\end{aligned}
$$

It is automated the above steps by implementing them in the form of a software algorithm and construct with it a diagram of the bearing capacity under the strength conditions on the central and centripetal compression and the tension for the section shown in Fig. 1, 2. It is accepted the characteristics of materials similar to those used in experimental studies. Steel yield strength $R_{y}=280$ $\mathrm{MPa}$, prism strength of concrete $R_{b}=19,6 \mathrm{MPa}$. To determine the load-carrying capacity, use the formula (1), but let's take into account only the steel part of the cross-section.

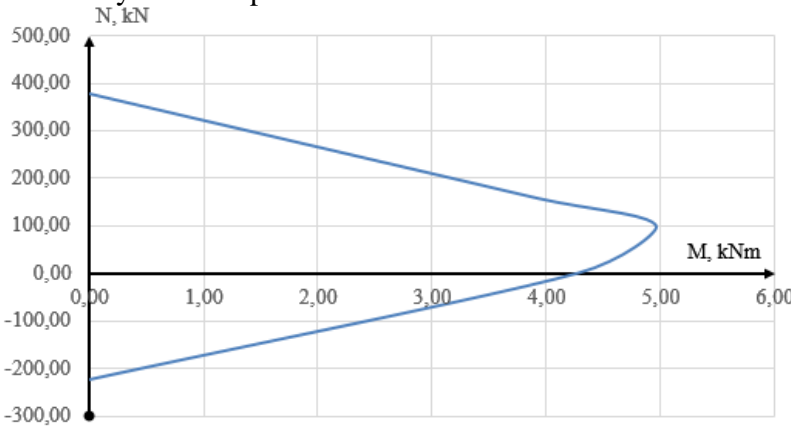

Fig. 13. Resistance capacity N-M for a steel-reinforced concrete section $100 \times 100 \mathrm{~mm}$ with a thickness of steel plates $4 \mathrm{~mm}$ chart.

In addition to determining the bearing strength, it is necessary to check the general and local stability of the steel reinforced concrete element. To determine the stability, let's give the crosssection to the tri-turbar by replacing the concrete core with the steel edge and determine its geometric characteristics - the area $A_{\text {red }}$, moment of resistance $W_{\text {red }}$, moment of inertia and radius of inertia $i$. For further calculations it will be taken geometric characteristics relative to the horizontal axis (the smallest) - as the worst possible case of stability loss. It should be noted that there are other options for reducing the cross-section, in particular, to box or twin-plate, but this reduces the flexibility of the column, which does not correspond to the data obtained during the experimental tests.

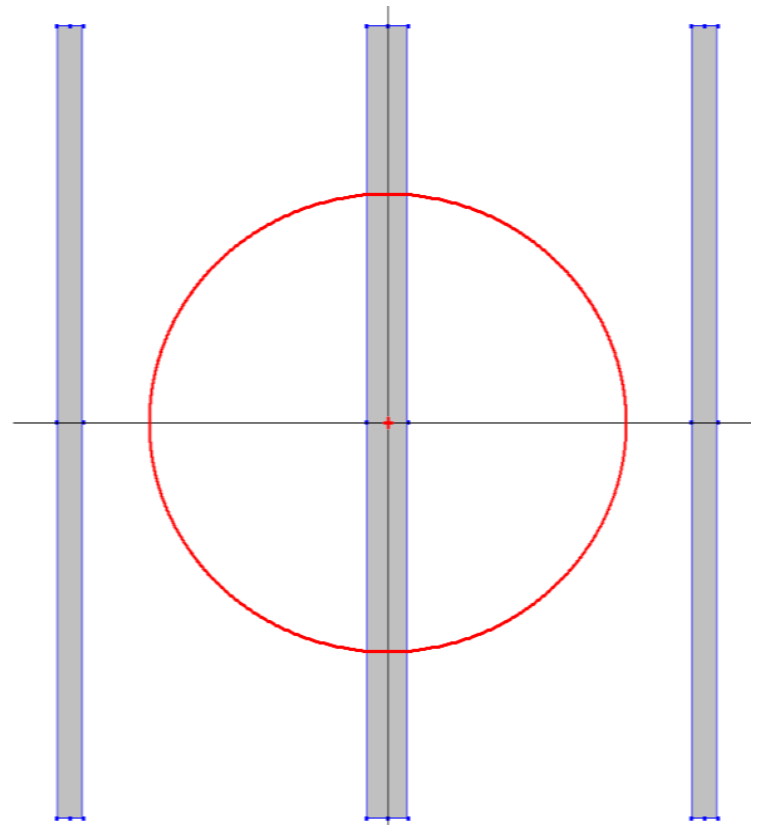

Fig. 14. The reduced section with the built in ellipse of inertia

To determine the stability of the central compression will use the formula (10):
$N-R_{y} \cdot A_{\text {red }} \cdot \varphi$

where $\varphi$ - the stability factor which depends on the element material characteristics $R_{y}$ and flexibility $\lambda$.

$\lambda=\mu \cdot l / i$

where $\mu$ - consolidation conditions coefficient, $l$ - element length.

Stable section off-center-compressed elements calculations of the on the overall stability in the plane of the momentum is performed according to the following formula:

$N=R_{y} \cdot A_{r e d} \cdot \varphi_{B}$,

Critical stress ratio $\varphi_{6}$

Depending on the combined relative eccentricity $\mathrm{m}_{\mathrm{ef}}$ and conditional flexion of the rod $\bar{\lambda}$.

$m_{e f}=\eta \cdot m$,

where $\eta$ - coefficient of influence of shape of a cross-section; $m$ - relative eccentricity:

$m=c \cdot A_{\text {red }} / W_{\text {red }}$

Conditional flexibility of the $\operatorname{rod} \bar{\lambda}$ :

$\bar{\lambda}=\mu \cdot l / i \cdot \sqrt{R_{y} / E}$

To ensure the local stability of steel reinforced concrete element should follow the recommendations Eurocode 4 check performance condition $h / t \prec 44 \cdot \sqrt{235 / R_{y}}$.

To verify the proposed method, compare the results of the bearing capacity obtained by the formulas $4,10,12$ with the experimental data of the test of steel-reinforced concrete elements of length $1 \mathrm{~m}$, $1,7 \mathrm{~m}$ та $2,4 \mathrm{~m}$ with a cross section $100 \times 100 \mathrm{~mm}$, with a thick steel wall $4 \mathrm{~mm}$ with the following characteristics $R_{y}=280 \mathrm{MPa}$, $E=207000 \mathrm{MPa}$ and concrete with prism strength $R_{b}=19,6$

$\mathrm{MPa}, E=24000 \mathrm{MPa}$. In tests, two criteria were selected for the bearing capacity of the steel reinforced concrete element. The first criterion was the state of the samples, in which the deformation of the steel walls corresponds to the deformations of the steel, which reached the yield strength $\left(N_{l}\right)$. The second is a state where a significant deformation of a deformation occurs at a constant or insignificant increase in loads, for example, - in fact, this state corresponds to the destruction of the steel reinforced concrete element $\left(N_{2}\right)$.

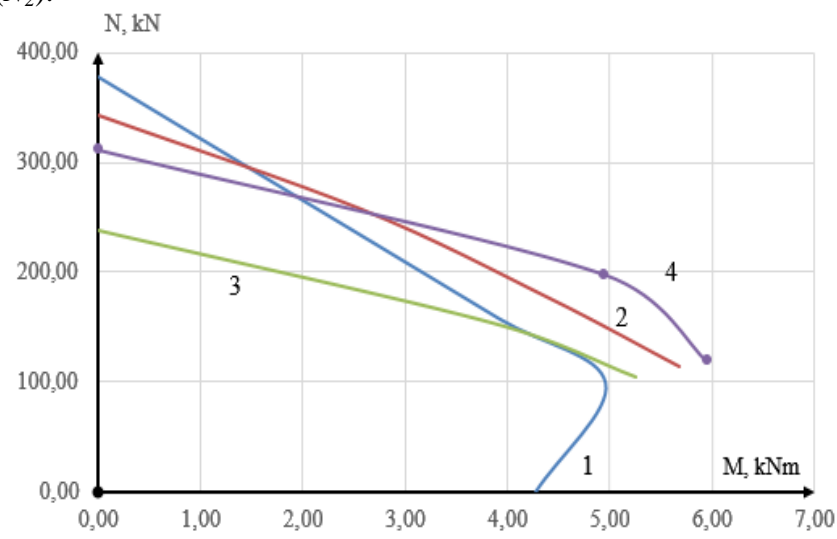

Fig. 15. Steel reinforced concrete elements $.1 \mathrm{~m}$ height bearing capacity: 
1 - Theoretical load bearing strength; 2 - theoretical bearing capacity for stability; 3 - bearing capacity experimental value from the reachieng conditions $\mathrm{N}_{1} ; 4$ - bearing capacity from the conditions of achievement $\mathrm{N}_{2}$

Resistance capacity characteristics $\mathrm{N}-\mathrm{M}$ for samples of height $1 \mathrm{~m}$ built on experimental tests and theoretical calculations results are presented in the Figure 15. It should be noted that for this length samples, the main reason for loss of bearing capacity was not the loss of stability, but the exceeding of the marginal strength of the cross section of the element.

Table 5. Experimental and theoretical load-bearing capacitycomparison

\begin{tabular}{|c|c|c|c|c|c|c|}
\hline $\begin{array}{l}\text { Se- } \\
\text { ries } \\
\text { sam- } \\
\text { ple }\end{array}$ & $\begin{array}{l}\text { Lengt } \\
\mathrm{h}, \mathrm{L} \text {, } \\
\mathrm{mm}\end{array}$ & $\begin{array}{l}\text { Eccen- } \\
\text { tricity } \\
\qquad e_{0}, \mathrm{~mm}\end{array}$ & $\begin{array}{c}\text { Test } \\
\text { bea- } \\
\text { ring } \\
\text { capaci- } \\
\text { ty, } \mathrm{N} 1 \text {, } \\
\text { кN }\end{array}$ & $\begin{array}{c}\text { Test } \\
\text { bea- } \\
\text { ring } \\
\text { capaci- } \\
\text { ty, N2, } \\
\text { кN }\end{array}$ & $\begin{array}{l}\text { Theor. } \\
\text { bea- } \\
\text { ring } \\
\text { capaci- } \\
\text { ty } \\
\text { (strengt } \\
\text { h) } \\
\mathrm{\kappa N}\end{array}$ & $\begin{array}{c}\text { Theoreti- } \\
\text { cal load } \\
\text { bearing } \\
\text { capacity } \\
\text { (stability) } \\
\text { кN }\end{array}$ \\
\hline $\begin{array}{l}\text { SB- } \\
\text { PD - } \\
10-1\end{array}$ & 1000 & 0 & 238 & 312 & 377,27 & $\begin{array}{c}343,3175 \\
2\end{array}$ \\
\hline $\begin{array}{l}\text { SB- } \\
\text { PD - } \\
10-2\end{array}$ & 1000 & 25 & 154 & 198 & 157,22 & $\begin{array}{c}176,1860 \\
24\end{array}$ \\
\hline $\begin{array}{l}\text { SB- } \\
\text { PD - } \\
10-3\end{array}$ & 1000 & 50 & 105 & 119 & 99,30 & $\begin{array}{c}113,5588 \\
72\end{array}$ \\
\hline $\begin{array}{l}\text { SB- } \\
\text { PD - } \\
17-1\end{array}$ & 1700 & 0 & 234 & 306 & 377,27 & $\begin{array}{c}302,1948 \\
72\end{array}$ \\
\hline $\begin{array}{l}\text { SB- } \\
\text { PD - } \\
17-2 \\
\end{array}$ & 1700 & 25 & 144 & 168 & 157,22 & $\begin{array}{c}148,2678 \\
96\end{array}$ \\
\hline $\begin{array}{l}\text { SB- } \\
\text { PD - } \\
17-3\end{array}$ & 1700 & 50 & 93 & 105 & 99,30 & 98,09072 \\
\hline $\begin{array}{l}\text { SB- } \\
\text { PD - } \\
24-1\end{array}$ & 2400 & 0 & 203 & 211 & 377,27 & $\begin{array}{c}241,0768 \\
08\end{array}$ \\
\hline $\begin{array}{l}\text { SB- } \\
\text { PD - } \\
24-2\end{array}$ & 2400 & 25 & 138 & 148 & 157,22 & $\begin{array}{c}122,9906 \\
72\end{array}$ \\
\hline $\begin{array}{l}\text { SB- } \\
\text { PD - } \\
24-3 \\
\end{array}$ & 2400 & 50 & 87 & 102 & 99,30 & $\begin{array}{c}84,13165 \\
6\end{array}$ \\
\hline
\end{tabular}

Experimental bearing capacity and theoretical strength comparison and stability are presented in the table 5.

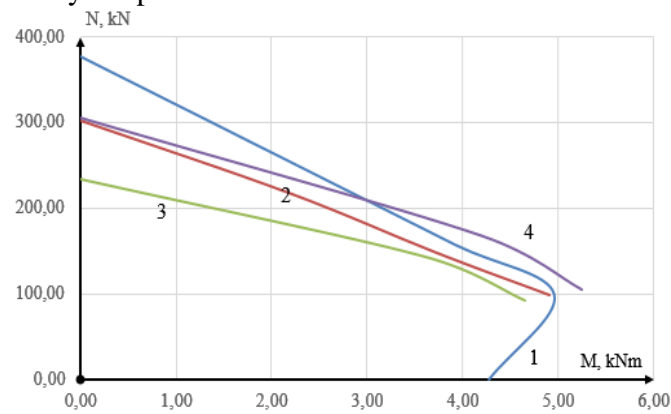

Fig. 16. Steel reinforced concrete elements $1,7 \mathrm{~m}$ height bearing capacity: 1 - Theoretical load bearing strength; 2 - theoretical bearing capacity for stability; 3 - experimental value of the bearing capacity from the reaching conditions $\mathrm{N}_{1} ; 4$ - bearing capacity from the conditions of achievement $\mathrm{N}_{2}$

Bearing capacity characteristics $\mathrm{N}-\mathrm{M}$ for samples of height $1,7 \mathrm{~m}$ built on experimental tests and theoretical calculations results are presented in the Figure 16. It is worth noting the fact that, for this length samples practically all loading application eccentricities, bearing capacity values were equal from overall stability strength or loss destruction conditions.

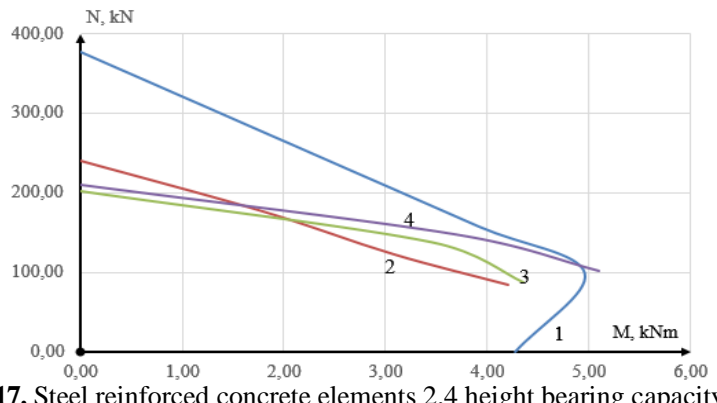

Fig. 17. Steel reinforced concrete elements 2,4 height bearing capacity: 1 - Theoretical load bearing strength; 2 - theoretical bearing capacity for stability; 3 - experimental value of the bearing capacity from the reaching conditions $\mathrm{N}_{1} ; 4$ - bearing capacity from the conditions of achievement $\mathrm{N}_{2}$ Resistance capacity characteristics $\mathrm{N}-\mathrm{M}$ for samples of height 2,7 $\mathrm{m}$ built on experimental tests and theoretical calculations results are presented on the Figure 17. For the series samples, the destruction cause was the loss of overall stability, which is confirmed by both experimental data and theoretical calculations.

\section{Conclusions}

Compressed flexible steel-reinforced concrete elements stressstrain state and bearing capacity important scientific study task is solved in the work. The investigation carried out in the work give reasons for the following conclusions:

1. A program was made and flexible steel reinforced concrete elements experimental studies were carried out. Steel sheets physical and mechanical properties and concrete-filling were determined. The strength of concrete test specimens is determined by testing 56 cubes $150 \times 150 \times 150 \mathrm{~mm}$ and prisms $150 \times 150 \times 600 \mathrm{~mm}$. Concrete prism strength was $R_{b}=19,6 \mathrm{MPa}$. Elasticity Initial module f $E_{b}=2,4 \times 10^{4} \mathrm{MPa}$.

2. It has been determined that in the case of sample experimental testing on central and eccentrical compression for short samples (length $1 \mathrm{~m}$ ) the destruction occurred due to cross section of the strength conditions reaching of the bearing capacit. Then as for long items (length 1,7 and 2,4 m) the prototype destruction was due to overall stability loss.

3. N-M steel-concrete structures for the limiting state at the reaching the boundary of the metal flow constructing non-iterative method coboundary dependences is presented. An algorithm is constructed and implemented in the form of a program for constructing steel-concrete section bearing capacity diagram, taking into account the concrete core compressed part, and made it possible to determine the tensile forces perceived by the joint element. $\mathrm{N}-\mathrm{M}$ for steel reinforced concrete elements bearing capacity diagrams are constructed.

\section{References}

[1] Comparison of results of experimental research of flexible rod composite reinforced concrete structure with sheet steel framework / L. Storozhenko, S. Murza, M. Beznigaev, O. Efimenko // Inżynieria Bezpieczeństwa Obiektów Antropogenicznych. - Bialostok, Poland, 2016. - P. $34-37$

[2] International research and practice conference / Modern methods, innovations, and experience of practical application in the field of technical sciences/ Radom, Republic of Poland, 2017 - 227p.

[3] Eurocode 4: Bemessung und Konstruktion von Verbund tragwerken ans ftahl und Beton. - E №V 1994. - 179 s.

[4] DBN B2.6.-160: 2010. Structures of buildings and structures. Steelconcrete constructions. Substantive provisions. - [Effective from 1 11-2011] - K .: Minregionbud of Ukraine, 2011. - 55 p.

[5] L.I. Storozhenko and H.M. Gasii, The new composite designs for mine tunnel support. Naukovyi Visnyk Natsionalnoho Hirnychoho Universytetu, no. 4, (2015), pp. 28-34.

[6] G. Gasii, O. Hasii, and O. Zabolotskyi, Estimate of technical and economic benefits of a new space composite structure. MATEC Web of Conferences, Vol. 116, (2017), pp. 02014, https://doi.org/10.1051/matecconf/201711602014 
[7] Schneider S.P. The Design and Construction of Concrete-Filled Steel Tube Column Frames / S. P. Schneider, D. R. Kramer, D. L. Sarkinnen // 13th World Conference on Earthquake Engineering. Vancouver, B.C., Canada. - Paper No. 252. - 2004.

[8] Xiao Y. Confined Concrete-Filled Tubular Columns / Y. Xiao, W. He, K. Choi. // Journal of Structural Engineering. - 2005. - N3. P.488-497.

[9] Li D. Analysis and Design of demountable steel column baseplate connections / D. Li, B. Uy, F. Aslani, V. Patel // Steel and Composite Structures Vol. 22. - 2016. - N4. - P.753-775.

[10] Zhao Y. G. System Reliability Assessment by Method of Moments / Y. G. Zhao, A. Ang // Journal of Structural Engineering. - 2003. N10. - P.1341-1349. 